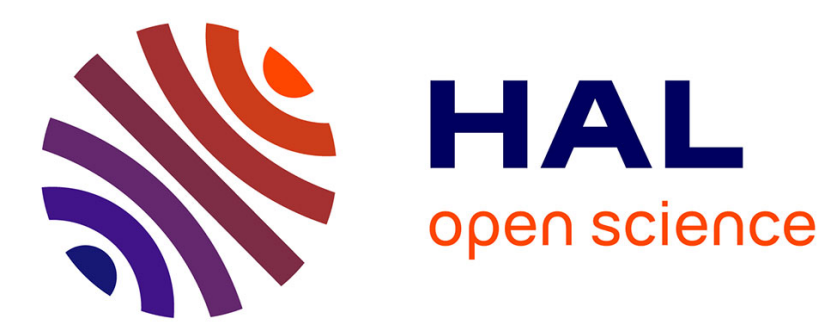

\title{
Silica based ionogels: interface effects with aprotic and protic ionic liquids with lithium
}

Angélique Marie, Bilel Said, Anne Galarneau, Timo Stettner, Andrea Balducci, Maxime Bayle, Bernard Humbert, Jean Le Bideau

\section{- To cite this version:}

Angélique Marie, Bilel Said, Anne Galarneau, Timo Stettner, Andrea Balducci, et al.. Silica based ionogels: interface effects with aprotic and protic ionic liquids with lithium. Physical Chemistry Chemical Physics, 2020, 22 (41), pp.24051-24058. 10.1039/d0cp03599h . hal-02988076

\section{HAL Id: hal-02988076 https://hal.science/hal-02988076}

Submitted on 25 Nov 2020

HAL is a multi-disciplinary open access archive for the deposit and dissemination of scientific research documents, whether they are published or not. The documents may come from teaching and research institutions in France or abroad, or from public or private research centers.
L'archive ouverte pluridisciplinaire HAL, est destinée au dépôt et à la diffusion de documents scientifiques de niveau recherche, publiés ou non, émanant des établissements d'enseignement et de recherche français ou étrangers, des laboratoires publics ou privés. 


\title{
Silica based ionogels: interface effects with aprotic and protic ionic liquids with lithium $\dagger$
}

\author{
Angélique Marie, ${ }^{a}$ Bilel Said, ${ }^{b}$ Anne Galarneau, ${ }^{b}$ Timo Stettner, ${ }^{c}$ Andrea Balducci, (D) \\ Maxime Bayle, ${ }^{a}$ Bernard Humbert (1) and Jean Le Bideau (D) *a
}

In the frame of the development of solid ionogel electrolytes with enhanced ion transport properties, this paper investigates ionogel systems constituted by $\sim 80 \mathrm{wt} \%$ of ionic liquids (ILs) confined in meso-/macroporous silica monolith materials. The anion-cation coordination for two closely related ILs, either aprotic (AIL) butylmethylpyrrolidinium or protic (PIL) butylpyrrolidinium, both with bis(trifluoromethylsulfonyl)imide (TFSI) anions, with and without lithium cations, is studied in depth. The ILs are confined within silica with well-defined mesoporosities ( 8 to $16 \mathrm{~nm}$ ). The effects of this confinement, onto melting points, onto conductivity followed by impedance spectroscopy, and onto lithium-TFSI coordination followed by Raman spectroscopy, are presented. Opposite effects have been observed on the melting temperature: it increased for the AlL $\left(+2{ }^{\circ} \mathrm{C}\right)$ upon confinement, while it decreased for the PIL $\left(-2^{\circ} \mathrm{C}\right)$. With lithium, the confinement led to an increase of the melting temperature $\left(+1{ }^{\circ} \mathrm{C}\right)$ for the PIL and AlL. Regarding ionic conductivities, a relative maximum was observed at $40{ }^{\circ} \mathrm{C}$ for a mesopore diameter of $10 \mathrm{~nm}$ for the AlL with $0.5 \mathrm{M}$ lithium, while it was not clearly visible for the PIL These differences are discussed in view of the charge balance at the interface between silanols and ILs: the presence of a PIL, contrary to an AIL, is expected to modify the acidity of the silica. Raman data showed that the coordination number of lithium by TFSI is reduced upon AIL confinement, although this was not observed for PILs. At last, this work highlights the impact of the acidity of a PIL on the chemistry occurring at the interface of the host network within ionogels.

\section{Introduction}

Ionic liquids (ILs) have been studied intensively for different purposes, from catalysts to sensors, energy storage devices, optical devices, etc. One of the key features of ILs is to be composed solely of ions, and to be at a liquid state below $100{ }^{\circ} \mathrm{C}$. This results in good dynamics and transport properties, ${ }^{1}$ very low flammability and low vapour pressures, making them highly attractive alternatives for conventional electrolytes for electrochemical storage devices. ${ }^{2}$ Different classes of ILs are of interest, owing to specific properties. Besides broadly studied aprotic ILs (AILs), protic ILs (PILs) represent a subclass of ILs displaying interesting properties originating from a possible "free" proton. Unlike AILs, charge conduction in PILs can be enhanced due to the association of Grotthuss (proton hopping) and vehicular (proton remain linked to a carrier) mechanisms. ${ }^{3,4}$ Although the largest field of application for PILs this far has been fuel cells, they still have been employed as electrolytes in several other energy storage devices. ${ }^{5}$

\footnotetext{
${ }^{a}$ Université de Nantes, CNRS, Institut des Matériaux Jean Rouxel, IMN, F-44000 Nantes, Franc.E-mail. jean.lebideau@cnrs-imn fr

${ }^{b}$ ICGM, Univ. Montpellier, CNRS, ENSCM, Montpellier, Frano

${ }^{c}$ Institute for Technical Chemistry and Environmental Chemistry,

Friedrich-Schiller-University, Jena, Philosophemveg 7a, 07743 Jena, Germany

$\dagger$ Electronic supplementary information (ESI) available. See DOI: 10.1039/d0cp03599h
}

Another general advantage of PILs is their synthesis, which is simpler as well as cheaper compared to the synthesis of AILs. ${ }^{6}$ They are obtained by proton transfer between a Brønsted acid and a Brønsted base. Theoretically, a full conversion of Brønsted molecules to ions is expected for a high $\mathrm{p} K_{\mathrm{a}}$ difference, based on aqueous measurements, between an acid and a base. Nevertheless, a high $\mathrm{p} K_{\mathrm{a}}$ difference in turn results in a high coulombic interaction between cations and anions, ${ }^{7}$ thus leading to strong interactions within cation-anion pairs or aggregates. Such strong interactions result in a decrease of the ionicity, i.e. an unintended decrease of the effective concentration of "free" ions. ${ }^{8}$ This affects the viscosity and the conductivity of the ILs.,10 Nevertheless, when associated with lithium, the free proton of PILs was shown to improve the lithium-ion mobility. ${ }^{11}$ Also, aggregated areas are commonly found in $\mathrm{Ls},{ }^{12}$ and confining the ILs allows breaking down of the aggregated regions, thus increasing the ionicity and favoring lithium conduction. ${ }^{13}$

The present study aims at comparing the anion-cation coordination of two closely related ILs, based on bis(trifluoromethylsulfonyl)imide (TFSI) anions and either $\mathrm{N}$-butyl $\mathrm{N}$ methylpyrrolidinium (AIL) or $N$-butylpyrrolidinium (PIL), with and without lithium-TFSI salt. These ILs are confined within meso-/macroporous silica monoliths with $2 \mu \mathrm{m}$ macropores and various mesopore diameters ranging from 8 to $16 \mathrm{~nm}$. The effects 
of this confinement onto the melting temperature, conductivity, and lithium-TFSI coordination, followed by Raman spectroscopy, are presented.

\section{Experimental}

Ionic liquids

The pyrrolidinium-based AIL $N$-butyl- $N$-methylpyrrolidinium bis(trifluoromethanesulfonyl)imide (Pyr14 TFSI) has been purchased from Iolitech ( $99 \%)$, LiTFSI from Aldrich (99.95\%). The pyrrolidinium-based PIL $N$-butyl-pyrrolidinium bis(trifluoromethanesulfonyl)imide (PyrH4 TFSI) was synthesized following a procedure similar to that described elsewhere. ${ }^{14,15}$ Two solutions at $0.5 \mathrm{M}$ LiTFSI were prepared in Pyr14 TFSI and PyrH4 TFSI. The water content of the ILs is lower than 40 ppm, as measured by Karl Fisher titration before DSC and conductivity measurements.

\section{Silica synthesis}

Hierarchical meso-/macroporous silica monoliths $(6 \mathrm{~mm}$ diameter and $10 \mathrm{~cm}$ length) with around $90 \%$ total porosity were synthesized accordingly to already published methods, ${ }^{16-18}$ which combines silica sol-gel synthesis in acidic medium $\left(\mathrm{HNO}_{3}\right)$ with spinodal decomposition, due to the addition of polymers (polyethylene oxide, $20 \mathrm{kDa}$ ) at $40{ }^{\circ} \mathrm{C}$. Hence, monoliths with macropores of $2.5 \mu \mathrm{m}$ diameter and a skeleton thickness of $3 \mu \mathrm{m}$ are obtained. By applying post-treatments in $\mathrm{NH}_{4} \mathrm{OH} 0.1 \mathrm{M}$ at different temperatures (from 40 to $80{ }^{\circ} \mathrm{C}$ ) and durations ( 6 to $24 \mathrm{~h}$ ) the mesopore diameters are adjusted from 8 to $16 \mathrm{~nm}$ (Table 1). All monoliths are calcined under air at $550{ }^{\circ} \mathrm{C}$ for $8 \mathrm{~h}$ to remove remaining polymers.

The macropore volumes, diameters and surface areas were measured by $\mathrm{Hg}$ porosimetry after outgassing the samples at room temperature. The mesopore volumes, diameters and surface areas were determined using nitrogen sorption isotherms at $77 \mathrm{~K}$ after outgassing the samples at $250{ }^{\circ} \mathrm{C}$.

\section{Ionogel preparation}

Silica monoliths were cut into pellets of around $3 \mathrm{~mm}$ high and $6 \mathrm{~mm}$ diameter. Before impregnation of ILs within silica, silica monoliths, ILs and ionogels were dehydrated overnight under $0.5 \mathrm{mbar}$ at $50^{\circ} \mathrm{C}$. Pellets were immersed in ILs for one week in closed vials. The same dehydration process was carried out prior to any characterization experiment.

\section{Calorimetry}

Phase transitions of bulk and confined ILs were studied by differential scanning calorimetry.

Table 1 Structural characteristics of silica monoliths before impregnation

\begin{tabular}{llllll}
$\begin{array}{l}\text { Silica } \\
\text { monolith }\end{array}$ & $\begin{array}{l}\left.\phi_{\text {meso(N }}\right) \\
(\mathrm{nm})\end{array}$ & $\begin{array}{l}S_{\mathrm{BET}\left(\mathrm{N}_{2}\right)} \\
\left(\mathrm{m}^{2} \mathrm{~g}^{-1}\right)\end{array}$ & $\begin{array}{l}V_{\left.\text {meso(N } \mathrm{N}_{2}\right)} \\
\left(\mathrm{cm}^{3} \mathrm{~g}^{-1}\right)\end{array}$ & $\begin{array}{l}V_{\text {macro(Hg) }} \\
\left(\mathrm{cm}^{3} \mathrm{~g}^{-1}\right)\end{array}$ & $\begin{array}{l}V_{\text {total }} \\
\left(\mathrm{cm}^{3} \mathrm{~g}^{-1}\right)\end{array}$ \\
\hline
\end{tabular}

\begin{tabular}{llllll}
\hline $40{ }^{\circ} \mathrm{C}-8 \mathrm{~h}$ & 8.1 & 636 & 0.97 & 1.99 & 2.96
\end{tabular}

$\begin{array}{llllll}40^{\circ} \mathrm{C}-13 \mathrm{~h} & 8.5 & 584 & 0.97 & 2.09 & 3.06\end{array}$

$\begin{array}{llllll}40^{\circ} \mathrm{C}-24 \mathrm{~h} & 9.8 & 546 & 1.03 & 2.22 & 3.25\end{array}$

$\begin{array}{llllll}50{ }^{\circ} \mathrm{C}-24 \mathrm{~h} & 11.2 & 540 & 1.06 & 2.29 & 3.35\end{array}$

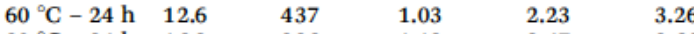

$\begin{array}{llllll}80{ }^{\circ} \mathrm{C}-24 \mathrm{~h} & 16.2 & 336 & 1.19 & 2.47 & 3.66\end{array}$
Few mg of ILs and ionogels were hermetically sealed in aluminium pans. After initial heating at $100{ }^{\circ} \mathrm{C}$, the samples were quenched down to $-100^{\circ} \mathrm{C}$ at a cooling rate of $\sim 30^{\circ} \mathrm{C} \mathrm{min}{ }^{-1}$. A first heating, up to $100{ }^{\circ} \mathrm{C}$, at $10^{\circ} \mathrm{C} \mathrm{min}^{-1}$ is applied and allows a simple observation of the heat capacity increase corresponding to the glass transition temperature, which is measured at the inflexion point. The samples were then cooled again to $-100{ }^{\circ} \mathrm{C}\left(\sim 30^{\circ} \mathrm{C} \mathrm{min}^{-1}\right)$ and heated at $2{ }^{\circ} \mathrm{C} \mathrm{min}{ }^{-1}$ to measure the temperature and the enthalpy of the cold crystallisation and melting. The melting temperature is taken at the maximum of the transition. For each sample (IIs and ionogels), the heat flow is given per mass unit of IL.

\section{Ionic conductivity}

The ionic conductivity of samples was studied by complex impedance spectroscopy (CIS) between $-20{ }^{\circ} \mathrm{C}$ and $90{ }^{\circ} \mathrm{C}$ using a VMP 3, Biologic. The amplitude voltage used was $7 \mathrm{mV}$ and the frequency range was $184-100 \mathrm{mHz}$.

\section{Raman spectroscopy}

Raman spectra were recorded with a standard Fourier-transform spectrometer (Bruker) using a $1064 \mathrm{~nm}$ Nd:YAG laser line. The laser power was set to $300 \mathrm{~mW}$, the spectral resolution to $2 \mathrm{~cm}^{-1}$ and each presented spectrum was an average of 400 scans.

\section{Results and discussion}

\section{Thermal behaviour}

The macroporosity of the hierarchical meso-/macroporous silica monolith supports was studied by SEM and $\mathrm{Hg}$ porosimetry and the mesoporosity using $\mathrm{N}_{2}$ adsorption/desorption isotherms at $77 \mathrm{~K}$ (Table 1). A typical SEM image is presented in Fig. S1 (ESI $\dagger$ ). Macropore diameters of the silica monoliths are around $2.5 \mu \mathrm{m}$ with a skeleton thickness of $3 \mu \mathrm{m}$, the macropore volume is around $2 \mathrm{~mL} \mathrm{~g}^{-1}$ and the macropore surface area is around $4 \mathrm{~m}^{2} \mathrm{~g}^{-1}$. The mesopore volume is around $1 \mathrm{~mL} \mathrm{~g}^{-1}$, which represents around one third of the total pore volume. The mesopore diameters increase from 8 to $16 \mathrm{~nm}$, with the increase of $\mathrm{NH}_{4} \mathrm{OH}$ post-treatment duration and temperature (Table 1), leading to a decrease in the surface area from 600 to $300 \mathrm{~m}^{2} \mathrm{~g}^{-1}$. All monoliths feature a silanol density of 5-6 SiOH per $\mathrm{nm}^{2}$ (calculated from Raman spectroscopy). The impregnated IL weight in silica is obtained from the difference between the weight of silica after IL impregnation and the weight of pristine dried silica. For each case, the $\mathrm{IL}$ weight represents more than $82 \%$ of the total weight of ionogels (Table S1, ESI $\dagger$ ) in accordance with a total pore filling.

The confinement of ILs in these hierarchical macroporous silica monolithic matrices with different mesoporosities leads to variations in their change-of-state temperatures, which can be studied by DSC. Heat rates at $10{ }^{\circ} \mathrm{C} \mathrm{min}{ }^{-1}$ and $2{ }^{\circ} \mathrm{C} \mathrm{min}{ }^{-1}$ are used in order to measure precisely (i) the heat capacity at the glass transition, and (ii) the cold crystallization and melting temperature, respectively. DSC scans for unconfined and confined Pyr14 TFSI are shown in Fig. 1. For the other studied ILs (Pyr14 Li-TFSI, PyrH4 TFSI, PyrH4 Li-TFSI) DSC scans are 

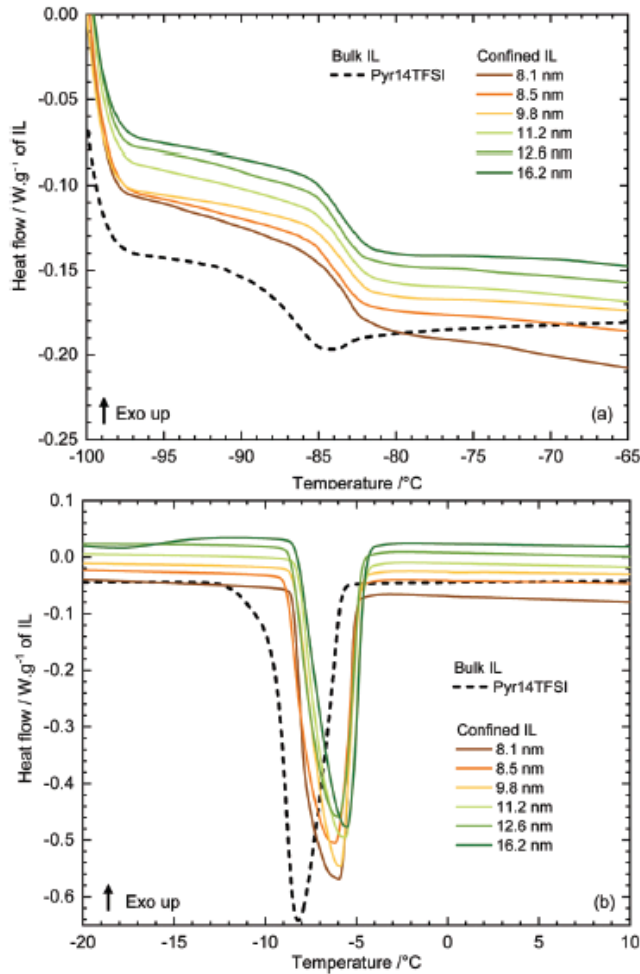

Fig. 1 DSC measurements for Pyr14 TFSI bulk and confined: (a) glass and (b) melting transitions. The heat flow is reported in relation to the mass of ILs. Curves are offset for visibility.

shown in Fig. S2 (ESI $\dot{\dagger}$ ). Table 2 summarizes the IL phase transitions (bulk and confined). ${ }^{19}$ Fig. 2 presents the evolution of the glass transition temperature, the calorific capacity variation during the glass transition, the melting transition temperatures, and the melting enthalpy, vs. the mesopore diameter. The glass transition temperatures $T_{\mathrm{g}}$ of Pyr14 TFSI, Pyr14-Li-TFSI, and PyrH4-Li-TFSI increase when the $\mathrm{IL}$ is confined in silica matrices, as shown in Fig. 1a and 2a. For confined and unconfined PyrH4 TFSI, the glass transition was not observed in the temperature range studied. The heat capacity modification $\Delta C_{\mathrm{p}}$ (Fig. 2b) of Pyr14 TFSI, either pure or containing Li, is not significantly modified by confinement, whereas the heat capacity of PyrH4 Li TFSI shows a larger increase. Nevertheless, the heat capacity of these three ILs seems to increase with the increase of mesopore diameter of the silica matrices. This appeared to be consistent with a decrease of surface to volume ratio, relatively less $\mathrm{IL}$ being constrained at the interface, thus allowing a macroscopic increase in entropy and thus an increase in heat capacity.

The variation in melting temperature $T_{\mathrm{m}}$ as a function of mesopore diameter is shown in Fig. 2c. The melting temperatures are $-8.2{ }^{\circ} \mathrm{C}$ and $+31.2{ }^{\circ} \mathrm{C}$ for Pyr14 TFSI and PyrH4 TFSI, respectively. Confinement effects in opposite manners for Pyr14 TFSI and PyrH4 TFSI were observed: confinement of Pyr14 TFSI resulted in an increased $T_{\mathrm{m}}$ of $1.9^{\circ} \mathrm{C}\left(T_{\mathrm{m}}^{\mathrm{c}}=-6.3{ }^{\circ} \mathrm{C}\right)$, whereas for PyrH4 TFSI confinement resulted in a decrease in melting temperature of about $1.5{ }^{\circ} \mathrm{C}\left(T_{\mathrm{m}}^{\mathrm{c}}=29.7{ }^{\circ} \mathrm{C}\right)$. Upon addition of $\mathrm{Li}$ salt, confinement of Pyr14-Li-TFSI showed an increase of $T_{\mathrm{m}}$ of $1.1{ }^{\circ} \mathrm{C}$ $\left(T_{\mathrm{m}}^{\mathrm{c}}=-9.4{ }^{\circ} \mathrm{C}\right)$; the confinement of PyrH4-Li-TFSI caused a very small $T_{\mathrm{m}}$ increase of about $0.8^{\circ} \mathrm{C}\left(T_{\mathrm{m}}^{\mathrm{c}}=25.7^{\circ} \mathrm{C}\right)$, unlike for neat PyrH4 TFSI, which showed a decrease of $1.5{ }^{\circ} \mathrm{C}$.

\begin{tabular}{lll}
\hline Sign of $\Delta T_{\mathrm{m}}$ upon confinement & Pyr14 TFSI & PyrH4 TFSI \\
\hline Without Li & $T_{\mathrm{m}}^{\mathrm{c}}>T_{\mathrm{m}}$ & $T_{\mathrm{m}}^{\mathrm{c}}<T_{\mathrm{m}}$ \\
With Li & $T_{\mathrm{m}}^{\mathrm{c}}>T_{\mathrm{m}}$ & $T_{\mathrm{m}}^{\mathrm{c}}>T_{\mathrm{m}}$
\end{tabular}

Upon addition of lithium, there is only a small difference between Pyr14 and PyrH4, with an increase of $T_{\mathrm{m}}$ of around $1{ }^{\circ} \mathrm{C}$ with confinement. However, it is without lithium that the difference is larger between the two ILs, with a $T_{\mathrm{m}}$ increase of $1.9^{\circ} \mathrm{C}$ for Pyr14 and a decrease of $-1.5^{\circ} \mathrm{C}$ for $\mathrm{PyrH} 4$ with confinement. Even if these differences are not decisive in terms of devices performances, the study of $T_{\mathrm{m}}$ variation allows us to better analyse and understand the interactions of the ILs with the silica surface. The interactions between the $\mathrm{IL}$ and the silica pore wall with the given chemistry is thus different between Pyr14 TFSI and PyrH4 TFSI. Moreover, these interactions at the II-silica interface are modified in the presence of Li cations. The Gibbs-Thomson model allows a rationalization of the melting/solidification temperature of confined ILs:

$$
\frac{T_{\mathrm{m}}^{\mathrm{c}}-T_{\mathrm{m}}}{T_{\mathrm{m}}}=2 \frac{\left(\gamma_{\mathrm{L}-\mathrm{I}}-\gamma_{\mathrm{S}-\mathrm{I}}\right) \nu}{r_{\text {meso }} \Delta_{\mathrm{m}} H}
$$

Table 2 Thermal properties of non-confined ILs and of values averaged over all pores size for confined ILS

\begin{tabular}{|c|c|c|c|c|}
\hline ILs & $T_{g} /{ }^{\circ} \mathrm{C}$ & $\Delta C_{\mathrm{p}} / \mathrm{J} \mathrm{g}^{-1} \mathrm{~K}^{-1}$ & $T_{\mathrm{m}}{ }^{a} /{ }^{\circ} \mathrm{C}$ & $\Delta_{\mathrm{m}} H / \mathrm{J} \mathrm{g}^{-1}$ \\
\hline Pyr14TFSI & -86.59 & 0.244 & -8.18 & 45.56 \\
\hline Confined & $-83.4 \pm 0.1$ & $0.26 \pm 0.01$ & $-6.3 \pm 0.6$ & $35.8 \pm 0.9$ \\
\hline \multicolumn{5}{|l|}{ Pyr14TFSI } \\
\hline Pyr14TFSI + 0.5 M LiTFSI & -76.05 & 0.274 & $-10.53(-7.53)$ & 40.59 \\
\hline Confined Pyr14TFSI + 0.5 M LiTFSI & $-74.5 \pm 0.6$ & $0.28 \pm 0.02$ & $-9.4 \pm 0.3$ & $29.8 \pm 0.8$ \\
\hline PyrH4TFSI & - & - & 31.36 & 59.95 \\
\hline Confined & - & - & $29.9 \pm 0.9$ & $51 \pm 2$ \\
\hline \multicolumn{5}{|l|}{ PyrH4TFSI } \\
\hline PyrH4TFSI + 0.5 M LiTFSI & -72.19 & 0.0276 & $(8.20) 24.9$ & 41.19 \\
\hline Confined PyrH4TFSI +0.5 M LiTFSI & $-70.9 \pm 0.7$ & $0.13 \pm 0.05$ & $25.7 \pm 0.1$ & $36 \pm 1$ \\
\hline
\end{tabular}

${ }^{a}$ Minor melting events are given in parenthesis, taken at the peak maximum. They are comprised of $\Delta_{\mathrm{m}} H$ values. 

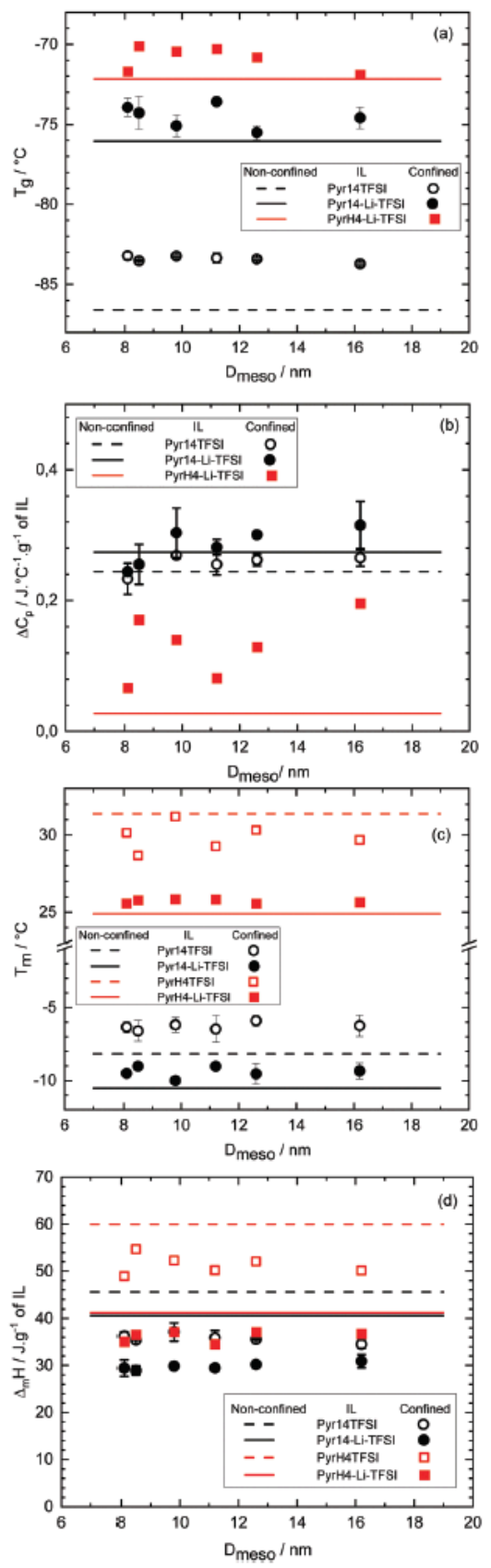

Fig. 2 DSC results for (a) glass transition, (b) calorific capacity variations during the glass transition, (c) melting temperature and (d) enthalpy of fusion for bulk and confined ILs. The heat flow is reported in relation to the mass of IL in the studied samples. Horizontal solid and dotted lines are eye guides referencing to non-confined ILs. with $T_{\mathrm{m}}^{\mathrm{c}}$ and $T_{\mathrm{m}}$ as the melting temperature of the confined and unconfined $\mathrm{IL}, \gamma_{\mathrm{S}-\mathrm{I}}$ and $\gamma_{\mathrm{L}-\mathrm{I}}$ as the interface energies between the silica wall and the IL depending on whether it is in the solid or liquid state, $\nu$ as the molar volume of the IL ( $\Delta \nu$ during phase change is neglected), $\Delta_{\mathrm{m}} H$ as the melting enthalpy of the unconfined $\mathrm{IL}$ and $r_{\text {meso }}$ as the pore radius. The interface energies $\gamma_{\mathrm{S}-\mathrm{I}}$ and $\gamma_{\mathrm{H}}$ are taken positive and are homogeneous at chemical potentials; the system spontaneously evolves towards a chemical potential decrease. If $\gamma_{\mathrm{S}-\mathrm{I}}<\gamma_{\mathrm{L}-\mathrm{I}}$, then $T_{\mathrm{m}}^{\mathrm{c}}>T_{\mathrm{m}}$ : the liquid state of the confined IL is unfavored. These are the situations of Li-free Pyr14 TFSI, and those of Pyr14 and PyrH4 with Li. If $\gamma_{\mathrm{S}-\mathrm{I}}>\gamma_{\mathrm{L}-\mathrm{I}}$, then $T_{\mathrm{m}}^{\mathrm{c}}<T_{\mathrm{m}}$ : the liquid state of the confined IL is favored. This is the situation of Li-free PyrH4 TFSI. The decrease of melting point upon confinement is classically observed for liquids with high affinity for the surface matrix as water in hydrophilic silica. ${ }^{20,21}$ It was also observed for $\mathrm{IL}$, such as hydrophilic 1-butyl-3-methylimidazollium $\left[\mathrm{CF}_{3} \mathrm{SO}_{3}\right]^{-} \mathrm{IL}$, in silica. ${ }^{22}$ Confinement can preserve the original liquid nature of some ILs at a much lower temperature than bulk $T_{\mathrm{m}}$. For water, a thin non freezable layer between the core ice and the pore walls exists at very low temperature and has been recently observed for silica and carbon supports. ${ }^{21}$

In other words, the physico-chemical affinity between the host network and the confined $\mathrm{IL}$ at liquid state is lower when $T_{\mathrm{m}}^{\mathrm{c}}>T_{\mathrm{m}}$ compared to when $T_{\mathrm{m}}^{\mathrm{c}}<T_{\mathrm{m}}$. For Pyr14 TFSI, the $T_{\mathrm{m}}$ increase indicates an attracting effect between Pyr14 TFSI at solid state and silica pores. In contrast, for PyrH4 TFSI, the $T_{\mathrm{m}}$ decrease upon confinement shows an attractive effect between PyrH4 TFSI at liquid state and the silica pores. The behaviors of Pyr14 and PyrH4 are similar to what is observed for a non-ionic and polarizable liquid, such as $\mathrm{CCl}_{4}$ confined, in graphite and in silica, respectively. ${ }^{23}$

For Pyr14-Li-TFSI and PyrH4-Li-TFSI, the melting temperature increased upon confinement (Fig. 2 and 3), as observed in a previous study. ${ }^{16}$ The presence of $\mathrm{Li}$ cations at the interface appears to decrease the interaction between the pyrrolidinium and TFSI ions with the silica pore walls. Thus, this is consistent

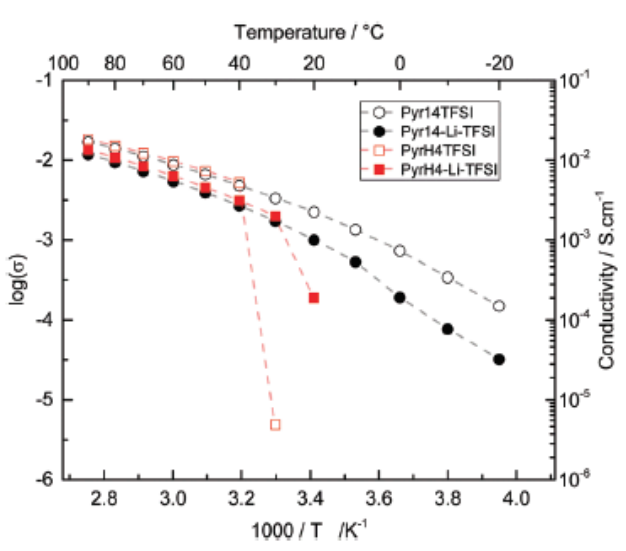

Fig. 3 Ionic conductivity of bulk ILs. Breaks on conductivity are due to melting transition of PyrH4 TFSI and PyrH4-LiTFSI (around $30^{\circ} \mathrm{C}$ ). 
with a high affinity of Li cations towards silica for both ILs. It is therefore no longer Pyr14 or PyrH4 which interacts with the silica wall, but a layer involving Li cations. This is consistent with previous studies, showing that Li cations preferentially move towards the interface between the $\mathrm{IL}$ and the pore wall. ${ }^{13} \mathrm{It}$ is also worth pointing out that confinement in silica shows stronger effects in the case of PyrH4, which might be due to the larger importance of $\mathrm{H}$-bonding within the $\mathrm{IL}$ and $\mathrm{SiO}-\mathrm{H}$ surface groups of silica, which disturbance is in turn compensated upon lithium addition by SiO-H-SiO-Li exchange. No dependency of melting temperature on the mesopore size was observed as expected by the Gibbs-Thompson model as the presence of the macropores averages the effect of the mesopores.

\section{Conductivity}

The ionic conductivity of bulk ILs is shown in Fig. 3. Above $40{ }^{\circ} \mathrm{C}$, the conductivities of Pyr14 TFSI and PyrH4 TFSI were very similar, with and without Li. As expected, the addition of Li TFSI decreased the conductivity. Upon cooling, a slope break appeared for PyrH4 based ILs due to the solid-to-liquid transition (at about $30^{\circ} \mathrm{C}$ ). For Pyr14-based ILs, this slope break is smaller and appeared at lower temperature (lower $T_{\mathrm{m}}$ ). The conductivity values of ILs are comparable with those obtained previously. ${ }^{10,24}$

Fig. 4 shows the conductivity of Pyr14 TFSI ionogels compared to that of the neat IL. For each ionogel, the conductivity was lower but showed the same behavior as that of the non-confined IL (Fig. S3, ESI + ). It is worth pointing out that the conductivity of the ionogels does not correspond to the intrinsic conductivity of confined ILs, since for a given form factor, the amount of IL in ionogels $(\sim 80 \mathrm{wt} \%)$ is lower than in unconfined ILs $(100 \mathrm{wt} \%) .{ }^{16}$ In order to study the conductivity independent of the volume of confined ILs, the molar conductivity is calculated for each nonconfined and confined IL. For confined ILs, the ionic conductivity $\left(\Lambda_{\text {confinedII }}\right)$ is calculated such as:

$$
\Lambda_{\text {confined IL }}=\frac{\sigma_{\text {inoogel }}}{V_{\text {IL }} / V_{\text {ionogel }}} \frac{M}{\rho}
$$

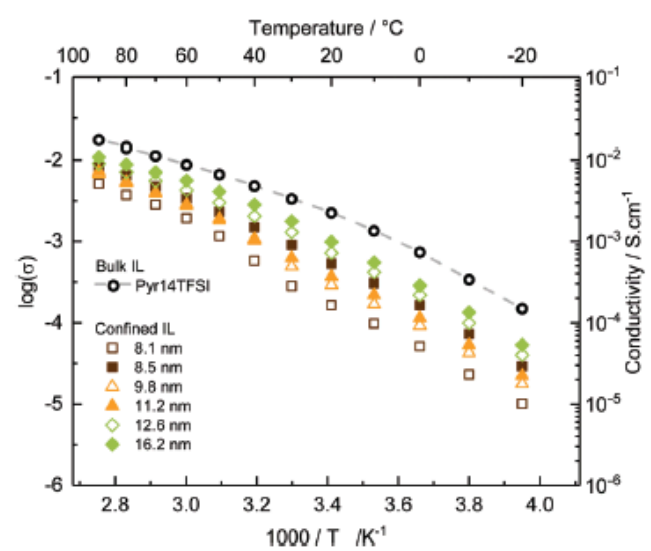

Fig. 4 Ionic conductivity of Pyr14TFSI ionogels, compared to the IL Pyr14TFSI. here, $\sigma_{\text {ionogel }}$ is the conductivity of the whole ionogel, $V_{\mathrm{II}}$ and $V_{\text {ionogel }}$ are the volumes of IL confined and the ionogel, $M$ is the molar mass and $\rho$ is the specific weight of the IL.

The molar conductivity $v s$. mesopore diameter at $40{ }^{\circ} \mathrm{C}$ is presented in Fig. 5. A similar pore size dependency was observed at the other temperatures. For AIL Pyr14 without lithium, the conductivity increases with mesopore diameter. A slight relative maximum occurs at around $10 \mathrm{~nm}$ for Pyr14-Li-TFSI, as already reported in a previous study with Pyr13-Li-TFSI confined in similar silica. ${ }^{5}$ The PIL PyrH4 with lithium does not show clearly any extremum at this temperature. In a previous work, we concluded that the dynamics of the silanol groups could help to create a diffusion path at the interface for the Li cation, and that the optimum mesopore diameter might indicate that the best diffusion of ions should occur when (i) the silica interface was saturated by lithium ions and when (ii) an almost equal ratio of ions was present at the surface of the pore and in the volume of the pore. This assumption was also proposed in catalysis, where the best compromise between the highest reactivity and the highest diffusion was estimated for an equal amount of molecules on the surface of the pore and in the volume of the pore (leading to an optimal mesopore diameter equal to 5-7 times the size of the molecule, calculated from the
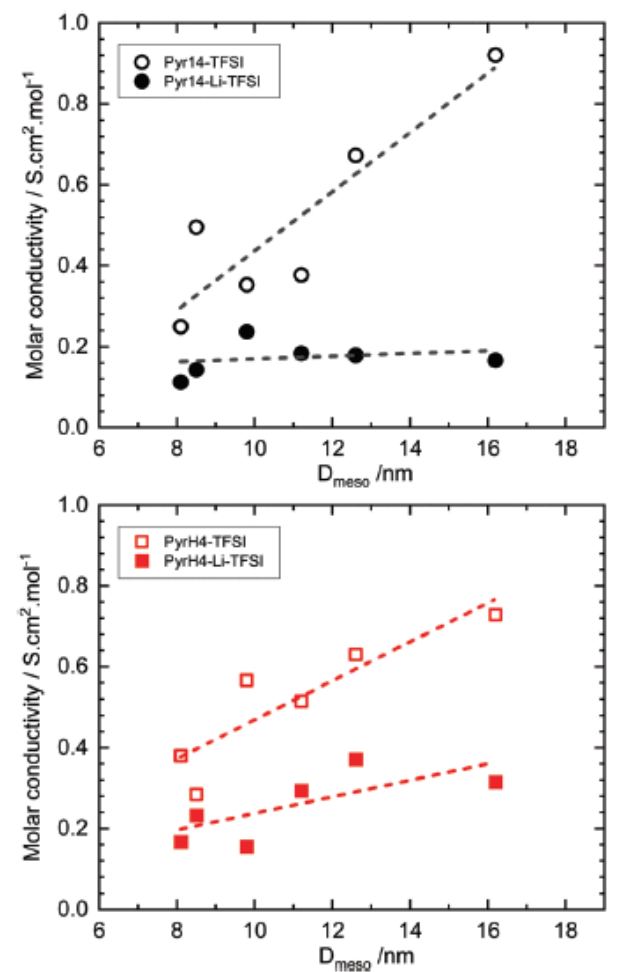

Fig. 5 Evolution of the molar conductivity of Pyr14 TFSI, PyrH4 TFSI, Pyr14-Li-TFSI and PyrH4-Li-TFSI with the confinement at $40{ }^{\circ} \mathrm{C}$. The molar conductivity is calculated as the conductivity normalized by the volume of IL confined in the silica matrices. Horizontal solid and dotted lines are eye guides showing the conductivities of non-confined ILs. 
Ruckenstein law) ${ }^{16}$ In the present study, carried out with the same silica and the same Li salt amount, we obtained the same result for the AIL Pyr14-Li-TFSI, showing sizes similar to that of Pyr13-Li-TFSI. For PIL PyrH4-Li-TFSI, the absence of clear extremum at $40{ }^{\circ} \mathrm{C}$ could be due to the drastic different effects of the AIL vs. PIL on the acidity of the silica This was recently shown for drastic different effects of the AIL and PIL on a series of para-substituted benzoic acids; there, the Hammett $\rho$ values for the acidic dissociation in some PILs were about the same as that in water but significantly smaller than that in the AIL..$^{25}$ Consequently, in the present study, the PIL should create an impactful amount of silanolate on the surface, thus decreasing drastically the ratio between the amount of $\mathrm{Li}$ cations and silanolate. An excessively large number of silanolate sites vs. the given amount of Li cations might turn into traps for part of the Li cations, or to strong interactions between PIL cations with the interface, at the expense of the release of the $\mathrm{Li}^{+}$from its coordination by TFSI. This is investigated below by means of Raman spectrometry.

\section{Raman spectroscopy study}

The interactions on a molecular scale at the interfaces can be investigated using Raman spectroscopy, through the study of the vibrational eigenmodes of our compounds. More specifically, the cisoid and transoid conformations of the TFSI anion (noted cis and trans hereafter): these are sensitive to the chemical environment and to the confinement, presenting different signatures. In this work, we focus our attention on the $720-765 \mathrm{~cm}^{-1}$ range of the Raman spectra.

In non-confined Pyr14 TFSI (inset in Fig. 6a), the symmetric elongation mode of the whole TFSI anion appears through the band located at $742 \mathrm{~cm}^{-1} \cdot{ }^{16,26,27}$ It should be noted that both $c i s$ and trans conformations participate in this contribution. ${ }^{28,29}$ This band shifts at about $744 \mathrm{~cm}^{-1}$ in the case of PyrH4 TFSI (inset in Fig. 6b), indicating an increase of the interactions between TFSI and the pyrrolidinium cations, which may be due to the presence of a hydrogen atom bonded to the nitrogen. ${ }^{11,24}$

Addition of lithium to the Pyr14 TFSI leads to the appearance of a shoulder on the previous band at about $748 \mathrm{~cm}^{-1}$, accounting for the coordination of $\mathrm{Li}^{+}$to TFSI. ${ }^{24,28,30}$ For PyrH4-Li-TFSI, this additional contribution merges with the band at $744 \mathrm{~cm}^{-1}$, giving an asymmetrical band shifted toward the higher wavenumbers.

The number of TFSI anions coordinating a $\mathrm{Li}^{+}$cation can be estimated using the ratio of the integrated intensity of the $748 \mathrm{~cm}^{-1}$ band $\left(A_{\text {coord }}\right)$ over the integrated intensity of the whole band $\left.\left(A_{\text {tot }}\right)\right)^{11,31}$ If we consider that all the $\mathrm{Li}^{+}$are coordinated by TFSI, its coordination number $\mathrm{CN}$ can be calculated

$$
\mathrm{CN}=\frac{A_{\text {coord }}}{A_{\text {tot }}} \times \frac{1}{x}
$$

with $x$ as the molar fraction of $\mathrm{Li}^{+}$in the IL (0.132 in Pyr14 TFSI and 0.125 in PyrH4 TFSI). To calculate these integrated intensities, the signal can be decomposed into two (one non-coordinated and one coordinated) or three (cis, trans and coordinated) components. This latter decomposition gives more precise results and is
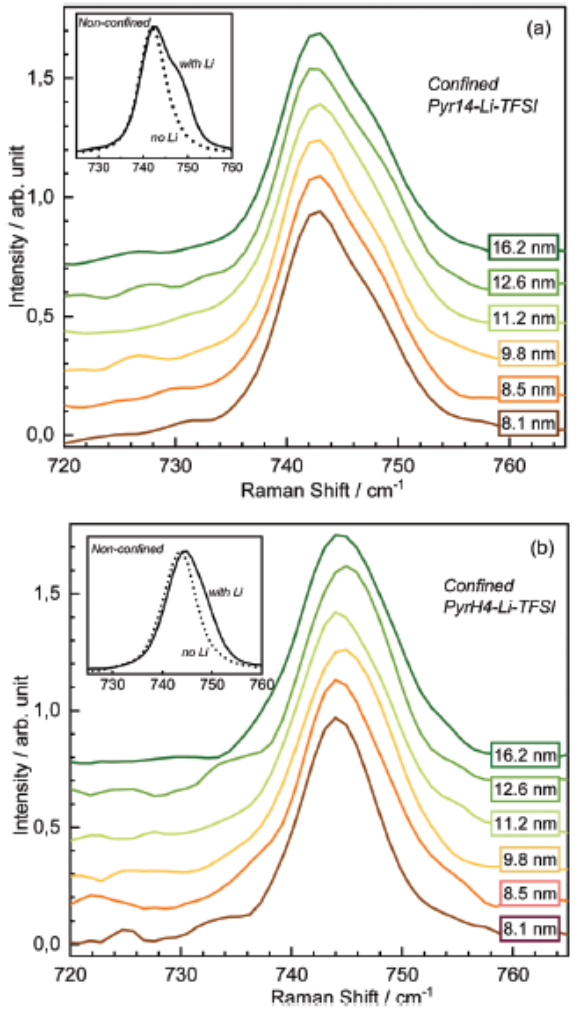

Fig. 6 Raman spectra of non-confined and confined ILs: (a) Pyr14-LiTFSI and (b) PyrH4-Li-TFSI. Raman spectra of neat ILs are added for comparison in dashed lines. Silica pore sizes are indicated in front of corresponding confined IL spectra. Spectra normalised on intensity maximum and shifted for visibility.

presented in Fig. 7. To support and confirm the choice of this method, a decomposition of the signal has also been performed using a Bayesian positive source separation algorithm (BPSS, Fig. S4, ESI + ). This unsupervised numerical approach gave the same results presented here, and thus are not detailed in this paper with a view to greater clarity and concision. For more information, one can find details in ref. 32 . It is to be noted that both approaches show only one band for the vibration mode of the coordinated species. This point does not allow further conclusion on the possible position difference between cis and trans configurations in the coordinated complexes.

For the Pyr14-Li-TFSI and PyrH4-Li-TFSI-based ionogels and ILs, the best fits of the Raman spectra were obtained using three pseudo-Voigt functions, named C1, C2 and Ccoord (details on the method and obtained parameters are available in Tables S2 and S3, ESI + ). For each non-confined IL spectrum, Ccoord parameters (relative intensities and positions) were in good agreement with the already reported results. ${ }^{11,24,33}$ For Pyr14Li-TFSI, the positions of cis and trans components have been reported to be separated by $2 \mathrm{~cm}^{-1}$, which is in agreement with the $1.3 \mathrm{~cm}^{-1}$ measured on our spectra between $\mathrm{C} 1$ and $\mathrm{C} 2$. 

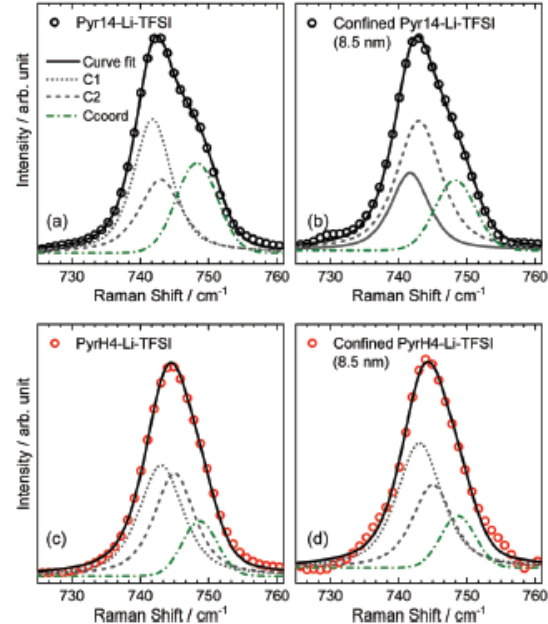

Fig. 7 Decomposition of Raman spectra of Pyr14-Li-TFSI and PyrH4-LiTFSI ( $a$ and $c$ ) non-confined and ( $b$ and d) confined in $8.5 \mathrm{~nm}$ silica pore. The $\mathrm{C} 1$ and $\mathrm{C} 2$ components represent $\mathrm{SI}$ conformations non-coordinating $\mathrm{Li}^{+}$, while Ccoord represent the TFSI conformations coordinating $\mathrm{Li}^{+}$.

The positions of cis and trans components in the above study were not reported for PyrH4 TFSI or PyrH4-Li-TFSI. Thus, the C1 and C2 fitted peaks could not be surely attributed to the cis and trans conformations. However, the sum of their integrated intensity remained a good representation of the non-coordinated conformations of TFSI.

The $\mathrm{CN}$ was evaluated with this method at 2.1 TFSI per $\mathrm{Li}^{+}$ for Pyr14-Li-TFSI and 1.1 TFSI per $\mathrm{Li}^{+}$for PyrH4-Li-TFSI (Fig. 8). For the same lithium-salt concentration (0.5 M LiTFSI), previous studies estimated a CN at 2 TFSI in Pyr14-Li-TFSI, and at 1.2 TFSI for PyrH4-Li-TFSI. ${ }^{11,24,33}$

For ILs confined in silica, two different behaviors emerged. For confined Pyr14-Li-TFSI, the CN decreased to $\sim 1.5$. On the other hand, the $\mathrm{CN}$ remained unchanged for PyrH4-Li-TFSI ( 1.2). The confinement of Pyr14-Li-TFSI lowered the interactions between TFSI and $\mathrm{Li}^{+}$due to a preferential interaction of $\mathrm{Li}^{+}$with silanolates. ${ }^{13,16}$ For confined PyrH4-Li-TFSI, it was not possible to observe clearly such an effect, maybe due to PIL

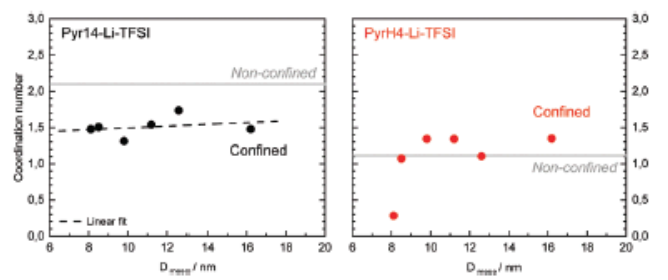

Fig. 8 Coordination number of $\mathrm{Li}^{+}$by TFSI in confined Pyr14-Li-TFSI (left) and PyrH4-Li-TFSI (right) compared to non-confined ILs (horizontal gray lines). In confinement, the coordination number of Pyr14-Li-TFSI decreases. There is no clear modification of the coordination number in confinement for PyrH4-Li-TFSI. interactions with silanolates, and to an average coordination of TFSI not only by lithium but also by protons.

\section{Conclusions}

Aprotic butylmethylpyrrolidinium bis(trifluoromethylsulfonyl)imide (AIL) and protic butylpyrrolidinium bis(trifluoromethylsulfonyl)imide (PIL) ionic liquids have been confined within a silica host network. Opposite effects on the melting temperatures have been observed; upon confinement, without lithium, it increased for the AIL, while it decreased for the PIL. With lithium, confinement still led to an increase of the melting temperature for the AIL, and in this case even for the PIL. Regarding ionic conductivities, at $40{ }^{\circ} \mathrm{C}$, a small relative maximum was found around pore sizes of $10 \mathrm{~nm}$ for the AIL with lithium. This might be due to the charge balance at the interface between silanols/silanolates and the ionic liquid: the presence of a PIL, contrary to an AIL, is expected to modify the acidity of the silica rather strongly. Thus the charge balance between ILs with a given amount of lithium salt and host network is modified. Raman data showed that the coordination number of lithium by bis(trifluoromethylsulfonyl)imide is reduced upon confinement of the AIL, although this was not observed when confining a PIL. This study also highlights the real impact of the acidity of a PIL on the chemistry occurring at the interface of the host network within ionogels, and gives knowledge for a better choice of host network for confined species adaptation in perspective of all solid devices.

\section{Conflicts of interest}

There are no conflicts to declare.

\section{References}

1 K. Hayamizu, S. Tsuzuki and S. Seki,J. Phys. Chem. A, 2008, 112, 12027-12036.

2 S. Wilken, S. Xiong, J. Scheers, P. Jacobsson and P. Johansson, J. Power Sources, 2015, 275, 935-942.

3 H. Watanabe, T. Umecky, N. Arai, A. Nazet, T. Takamuku, K. R. Harris, Y. Kameda, R. Buchner and Y. Umebayashi, J. Phys. Chem. B, 2019, 123, 6244-6252.

4 J. Ingenmey, S. Gehrke and B. Kirchner, ChemSusChem, 2018, 11, 1900-1910.

5 T. L. Greaves and C. J. Drummond, Chem. Rev., 2015, 115, 11379-11448.

6 M. Hirao, H. Sugimoto and H. Ohno, J. Electrochem. Soc., 2000, 147, 4168.

7 K. Ueno, Z. Zhao, M. Watanabe and C. A. Angell, J. Phys. Chem. B, 2012, 116, 63-70.

$8 \mathrm{~K}$. Ueno, H. Tokuda and M. Watanabe, Phys. Chem. Chem. Phys., 2010, 12, 1649-1658.

9 L.-M. Wang, C. A. Angell and R. Richert, J. Chem. Phys., 2006, 125, 074505.

10 T. Vogl, P. Goodrich, J. Jacquemin, S. Passerini and A. Balducci, J. Phys. Chem. C, 2016, 120, 8525-8533. 
11 S. Menne, T. Vogl and A. Balducci, Phys. Chem. Chem. Phys., 2014, 16, 5485-5489.

12 C. D'Agostino, M. D. Mantle, C. L. Mullan, C. Hardacre and L. F. Gladden, ChemPhysChem, 2018, 19, 1081-1088.

13 A. Guyomard-Lack, P.-E. Delannoy, N. Dupré, C. V. Cerclier, B. Humbert and J. Le Bideau, Phys. Chem. Chem. Phys., 2014, 16, 23639-23645.

14 T. Stettner, F. C. Walter and A. Balducci, Batteries Supercaps, 2019, 2, 55-59.

15 L. Timperman, P. Skowron, A. Boisset, H. Galiano, D. Lemordant, E. Frackowiak, F. Béguin and M. Anouti, Phys. Chem. Chem. Phys., 2012, 14, 8199-8207.

16 A. Guyomard-Lack, B. Said, N. Dupré, A. Galarneau and J. Le Bideau, New J. Chem., 2016, 40, 4269-4276.

17 A. Galarneau, Z. Abid, B. Said, Y. Didi, K. Szymanska, A. Jarzębski, F. Tancret, H. Hamaizi, A. Bengueddach, F. Di Renzo and F. Fajula, Inorganics, 2016, 4, 9.

18 A. Galameau, A. Sachse, B. Said, C.-H. Pelisson, P. Boscaro, N. Brun, L. Courtheoux, N. Olivi-Tran, B. Coasne and F. Fajula, C. R. Chim., 2016, 19, 231-247.

19 M. Kunze, S. Jeong, E. Paillard, M. Winter and S. Passerini, J. Phys. Chem. C, 2010, 114, 12364-12369.

$20 \mathrm{~K}$. Morishige, H. Yasunaga and Y. Matsutani, J. Phys. Chem. C, 2010, 114, 4028-4035.

21 K. Morishige, J. Phys. Chem. C, 2018, 122, 5013-5019.
22 M. Kanakubo, Y. Hiejima, K. Minami, T. Aizawa and H. Nanjo, Chem. Commun., 2006, 1828-1830.

23 L. D. Gelb, K. E. Gubbins, R. Radhakrishnan and M. SliwinskaBartkowiak, Rep. Prog. Phys., 1999, 62, 1573-1659.

24 T. Vogl, S. Menne, R.-S. Kühnel and A. Balducci, J. Mater. Chem. A, 2014, 2, 8258-8265.

25 F. Gao, P. Ji and J.P. Cheng, J. Org. Chem., 2020, 85, 3041-3049.

26 Y. Umebayashi, T. Mitsugi, K. Fujii, S. Seki, K. Chiba, H. Yamamoto, J. N. Canongia Lopes, A. A. H. Pádua, M. Takeuchi, R. Kanzaki and S. Ishiguro, J. Phys. Chem. B, 2009, 113, 4338-4346.

27 M. Herstedt, W. A. Henderson, M. Smirnov, L. Ducasse, L. Servant, D. Talaga and J. C. Lassègues, J. Mol. Struct, 2006, 783, 145-156.

28 J. C. Lassègues, J. Grondin, R. Holomb and P. Johansson, J. Raman Spectrosc., 2007, 38, 551-558.

29 A. Martinelli, Eur. J. Inorg. Chem., 2015, 1300-1308.

30 M. Kunze, S. Jeong, E. Paillard, M. Schönhoff, M. Winter and S. Passerini, Adv. Energy Mater., 2011, 1, 274-281.

31 J.-C. Lassègues, J. Grondin and D. Talaga, Phys. Chem. Chem. Phys., 2006, 8, 5629-5632.

32 C. Carteret, A. Dandeu, S. Moussaoui, H. Muhr, B. Humbert and E. Plasari, Cryst. Growth Des., 2009, 9, 807-812.

33 J. Pitawala, A. Martinelli, P. Johansson, P. Jacobsson and A. Matic, J. Non-Cryst. Solids, 2015, 407, 318-323. 